\title{
The Second European Conference on Mental Health and Deafness*
}

\author{
KeN CheCINSKI, Senior Registrar in Psychiatry, St George's Hospital, London SW17
}

Two hundred and seventy deaf and hearing professionals converged on Namur, Belgium, to reaffirm the commitment of the First European Congress, held in 1988. British delegates in 1988 agreed that a psychiatric service for deaf children was overdue: this service is being established now. The needs of dangerous and offender deaf patients in Britain were unmet: Rampton Hospital is developing a service in a secure hospital setting. The two supra-regional psychiatric deaf units (at Whittingham Hospital, Preston, and Springfield Hospital, London) have developed their links with existing rehabilitation services and with non-NHS organisations: several community care ventures have started.

The theme of this congress was the importance of taking pan-European perspective, in the context of a service aimed at $0.1 \%$ of the general population. This approach can lead to the "empowerment" of deaf people: the "Helios" project is pursuing this aim. Current and future trends in psychiatric services for deaf people were discussed from an historical point of view by one of the pioneers of psychiatry for deaf people, Professor John Rainer, who was intimately involved in the establishment of a service in the 1950s in the United States. The WHO 'Health for All' campaign for equity across geographical, cultural and other boundaries was cited in support of improving services for deaf people, given the importance of social protective and risk factors in mental health.

Planning and establishing new mental health services for deaf people is complicated: Dr Inez Sleeboom described the process of the germination and growth of a service in the Netherlands, using knowledge gleaned from other countries. Twice as many staff are needed in comparison with a general psychiatric service. Emphasis was laid on methodologically sound research to aid planning of appropriate, accessible services. The congress was updated on the progress of the European ComacHSR project: terminology has been clarified. The project working party now will address diagnostic

*Held in Namur, Belgium, from 9-11 May 1991. and treatment issues, demographic aspects of deafness and psychiatric disorder, the views of deaf people themselves, and planned service developments. Multiple-handicapped deaf people present particular therapeutic challenges: the term "deaf" encompasses a vast range of abilities, so that the multidisciplinary approach is essential.

Fourteen workshops were held: nine of these had a British co-leader. Subjects of particular interest included forensic aspects, family therapy rehabilitation, child psychopathology, movement in diagnosis and treatment, issues in research methodology, and the experience of deaf mental health professionals. Fringe meeting and poster presentation topics included the fledgling service for deaf patients at Rampton Hospital, and a project examining the relationship between cerebral function, sign language and schizophrenic thought disorder.

Throughout the congress, speakers underlined the importance of understanding psychosocial and developmental factors, and that deaf people must play a key role in future developments and should be involved in staff training. The Open University has introduced a course module in deaf social studies. Projects such as the counselling course for deaf trainees established at the Westminster Pastoral Foundation, London, are starting to address the lack of training opportunities in this highly specialised area.

Following the congress, the European Society for Mental Health and Deafness elected Dr Nick Kitson, consultant psychiatrist at St George's and Springfield Hospitals, London, as its president. A multidisciplinary conference will be held in November 1991, at St George's Hospital Medical School, London, to establish a British Society for Mental Health and Deafness.

Author's note on terminology: The term "deaf" is used to describe those people whose deafness began usually in early life, and is so marked that they might use signing as their language of choice. It is meant to convey a sense of deaf cultural identity. 